Article

\title{
First-Principles Study on III-Nitride Polymorphs: AlN/GaN/InN in the Pmn2 1 Phase
}

\author{
Zheren Zhang $\mathbb{D}^{\mathbb{D}}$, Changchun Chai, Wei Zhang * $\mathbb{D}^{\mathbb{D}}$, Yanxing Song, Linchun Kong and Yintang Yang \\ School of Microelectronics, Xidian University, Xi'an 710071, China; zheren950323@gmail.com (Z.Z.); \\ ccchai@mail.xidian.edu.cn (C.C.); syx739686768@163.com (Y.S.); 15129180614@163.com (L.K.); \\ ytyang@xidian.edu.cn (Y.Y.) \\ * Correspondence: wzhang-1993@stu.xidian.edu.cn or zw_xidian@163.com
}

Received: 27 May 2020; Accepted: 14 July 2020; Published: 19 July 2020

\begin{abstract}
The structural, mechanical, and electronic properties, as well as stability, elastic anisotropy and effective mass of AlN/GaN/InN in the $P m n 2_{1}$ phase were determined using density functional theory (DFT). The phonon dispersion spectra and elastic constants certify the dynamic and mechanical stability at ambient pressure, and the relative enthalpies were lower than those of most proposed III-nitride polymorphs. The mechanical properties reveal that $P m n 2_{1}$-AlN and $P m n 2_{1}$-GaN possess a high Vickers hardness of $16.3 \mathrm{GPa}$ and $12.8 \mathrm{GPa}$. Pmn $2_{1}-\mathrm{AlN}, P m n 2_{1}-\mathrm{GaN}$ and $P m n 2_{1}-\mathrm{InN}$ are all direct semiconductor materials within the HSE06 hybrid functional, and their calculated energy band gaps are $5.17 \mathrm{eV}, 2.77 \mathrm{eV}$ and $0.47 \mathrm{eV}$, respectively. The calculated direct energy band gaps and mechanical properties of AlN/GaN/InN in the $P m n 2_{1}$ phase reveal that these three polymorphs may possess great potential for industrial applications in the future.
\end{abstract}

Keywords: III-Nitride; $P m n 2_{1}$ phase; density functional theory; electronic properties; mechanical properties; anisotropic properties

\section{Introduction}

Third-generation semiconductor materials have been of great interest in the past decade because of their importance in scientific research and their industrial applications [1-6]. Group III-V compound semiconductors are among the most widely used third-generation semiconductor materials, represented by $\mathrm{GaN}, \mathrm{AlN}, \mathrm{SiC}$ and diamond. These semiconductor materials have some common advantages, such as wide band gap, high electron saturation rate, high radiation resistance, high thermal conductivity, and high electric field [7-10]. Thus, they have important technological applications in optoelectronic devices, light-emitting diodes (LEDs), high-frequency electronic devices, radiation-resistant electronic devices and high-power electronic devices.

First-principles calculations based on density functional theory (DFT) are among the most reliable and popular microscopic theories in material science. This method has a high ability to predict the material structures and properties [11-20]. Yang et al. [21] predicted a novel high-pressure superhard BN phase at high pressure through a developed particle swarm optimization (PSO) algorithm. The calculations revealed that its Vickers hardness is $47 \mathrm{GPa}$, which is characteristic of a superhard material. Liu et al. [22] proposed three new metastable phases $\left(\mathrm{P}_{4} 22, \mathrm{C} 222, \mathrm{Pbca}\right.$, and $\left.\mathrm{I} \overline{4} 3 \mathrm{~d}\right)$ for AlAs. The electronic band structure calculation reveals $I \overline{4} 3 \mathrm{~d}-\mathrm{AlAs}$ is a direct semiconductor material with energy band gap of $1.76 \mathrm{eV}$, whereas $\mathrm{C} 222$ - and $\mathrm{P}_{4} 22$-AlAs are indirect semiconductor materials with band gaps of $0.47 \mathrm{eV}$ and $1.36 \mathrm{eV}$, respectively. $\mathrm{Xu}$ et al. [23] calculated the mechanical and thermodynamic properties of AlN/AlP/AlAs compounds in wurtzite, zinc-blende, and rock-salt structures through first-principles calculations. They found the hardness and Debye temperatures both decrease with the $X(X=N, P, A s)$ atomic number. Zhang et al. [24] studied the physical properties of four 
III-Nitride compounds, one indirect semiconductor material $(P m-3 n-\mathrm{BN})$ and three direct semiconductor materials (Pm-3n-AlN, $P m-3 n$-GaN, and $P m-3 n$-InN). The band gaps of $P m-3 n$-BN/AlN/GaN/InN are $1.04 \mathrm{eV}, 2.40 \mathrm{eV}, 3.27 \mathrm{eV}$ and $5.87 \mathrm{eV}$, respectively. Compared with the previous materials (AlGaAs, $\mathrm{AlGaN}, \mathrm{GaAsP}, \mathrm{AlGaInP}$ quaternary semiconductor alloy, or AlGaN and other ternary semiconductor alloys), they save the trouble of making ternary or quaternary semiconductors in semiconductor technology [24]. The materials in the Pmn2 1 phase, such as $\mathrm{Li}_{2} \mathrm{FeSiO}_{4}$, have been recognized as potential cathode materials for Li-ion batteries and have attracted the attention of many researchers [25-27] because of their safety, benign element composition and high theoretical energy density. Yang et al. [28] analyzed the structural, elastic, thermodynamic, optical and electronic properties of $\mathrm{B}_{1-x} \mathrm{Al}_{x} \mathrm{~N}$ in the $P m n 2_{1}$ phase by using density functional theory. Chittari [29] studied the dynamic stability of the $P m n 2_{1}$ phase of $\mathrm{NH}_{3} \mathrm{BH}_{3}$ by van der Waals-corrected density functional theory.

In this work, we propose two polymorphs of the III-Nitride compound semiconductor in the $P m n 2_{1}$ phase, GaN and InN, together with the AlN [30]. Their structural, mechanical, and electronic properties, as well as stability, elastic anisotropy, and effective mass are studied by density functional theory (DFT) [31]. All three polymorphs have direct band gaps and are mechanically and dynamically stable. The two-dimensional (2D) and three-dimensional (3D) perspectives of Young's modulus, together with universal anisotropic index $\left(A^{\mathrm{U}}\right)$ are used to analyze mechanical anisotropy.

\section{Computational Methods}

For the modeling of the $\mathrm{AlN} / \mathrm{GaN} / \mathrm{InN}$ in the $P m n 2_{1}$ phase, we use density functional theory (DFT)-based methods [31] realized in the plane-wave pseudopotential approach in the Cambridge Sequential Total Energy Package (CASTEP) codes [32]. The generalized gradient approximation (GGA) of the Perdew-Burke-Ernzerhof (PBE) [33] scheme and the local density approximation (LDA) [34,35] were used to optimize the geometry and calculate elastic constants.

The values of the cutoff energies are set as $280 / 330 / 350 \mathrm{eV}$ for AlN/GaN/InN in the $P m n 2_{1}$ phase, with k-point samplings with $0.025 \AA^{-1}(13 \times 3 \times 7 / 11 \times 3 \times 6 / 13 \times 3 \times 7)$ in the first irreducible Brillouin zone for $P m n 2_{1}$-AlN, $P m n 2_{1}-\mathrm{GaN}$ and $P m n 2_{1}-\mathrm{InN}$. The geometry optimization parameters were determined using the Broyden-Fletcher-Goldfarb-Shenno (BFGS) algorithm [36], with the following convergence tolerance: displacement of atoms during the geometry optimization less than $0.0005 \AA$, energy change less than $5 \times 10^{-6} \mathrm{eV}$ per atom, stress less than $0.02 \mathrm{GPa}$, and residual force below $0.01 \mathrm{eV} / \AA$. The phonon frequencies were calculated using linear response theory [37]. We used the Heyd-Scuseria-Ernzerhof (HSE06) hybrid functional [38] to calculate electronic band structures and partial density of state (PDOS) based on the optimized geometry.

\section{Results}

\subsection{Structural Properties}

Figure 1 shows the crystal structure of the predicted $P m n 2_{1}-\mathrm{AlN} / \mathrm{GaN} / \mathrm{InN}$ in different views and forms. This structure belongs to the $P m n 2_{1}$ space group of the orthorhombic system. The structure of $P m n 2_{1}$-AlN/GaN/InN consists of $\mathrm{sp}^{3}$-bonded rings in three different shapes. Figure $1 \mathrm{a}, \mathrm{c}$ shows the four-, six-, and eight-membered rings consisting of $\mathrm{Al} / \mathrm{Ga} / \mathrm{In}$ atoms and $\mathrm{N}$ atoms along two different views. Figure $1 \mathrm{~b}$ shows the six-membered rings, which can form a honeycomb-like structure. Figure $1 \mathrm{c}$ shows that three four-membered $\mathrm{Al} / \mathrm{Ga} / \mathrm{In}-\mathrm{N}$ rings are located by the eight-membered ring, and another four-membered $\mathrm{Al} / \mathrm{Ga} / \mathrm{In}-\mathrm{N}$ ring is located by the top of the six-membered ring. There are eight atoms in the conventional cell of $P m n 2_{1}$-AlN, and all atoms occupy the crystallographic $2 a$ sites in a conventional cell, as follows: Al: $(0.0,0.463,0.176) ;(0.5,0.208,0.316) ;(0.5,0.041,0.815) ;(0.5,0.714$, 0.315). N: $(0.0,0.462,0.798) ;(0.5,0.208,0.692) ;(0.5,0.041,0.193) ;(0.5,0.713,0.695)$. The atomic Wyckoff positions for $P m n 2_{1}$-GaN and $P m n 2_{1}$ - InN can be obtained by replacing the position of $\mathrm{Al}$ with $\mathrm{Ga}$ and In atoms. 
(a)

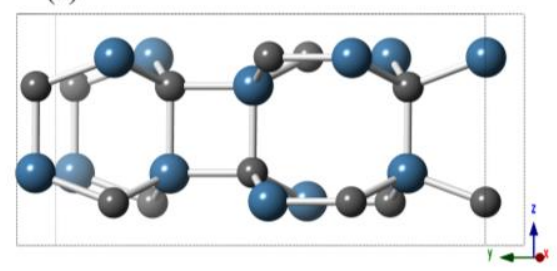

(c)

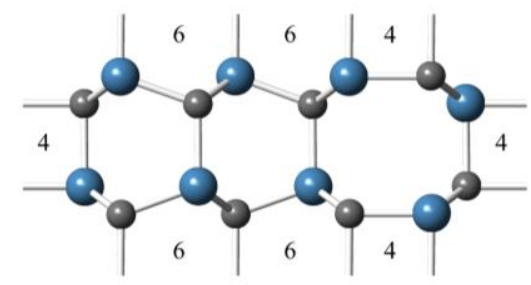

(d)
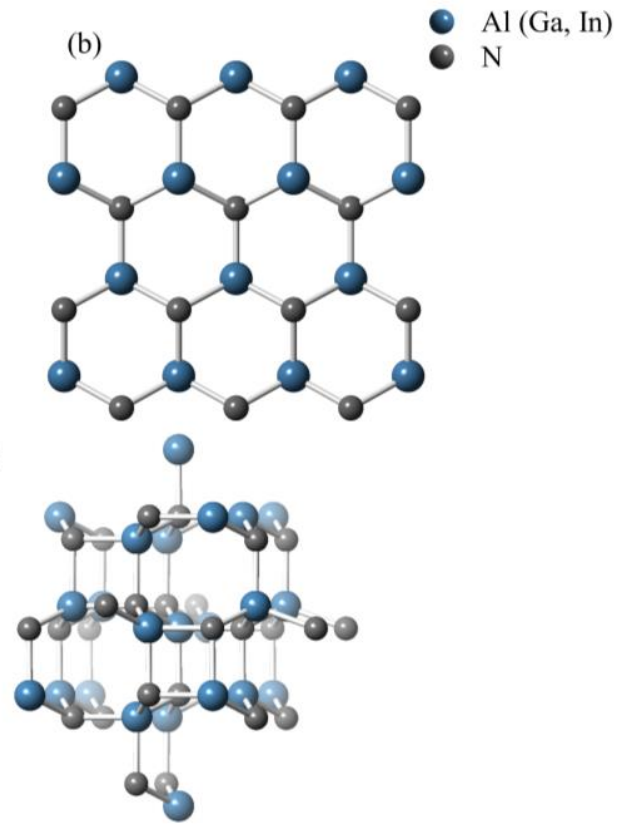

Figure 1. The structures of $\mathrm{AlN} / \mathrm{GaN} / \mathrm{InN}$ in the $P m n 2_{1}$ phase at ambient pressure: (a) unit cell of the crystal structure; views of the supercell structure along the (b) [001] direction, (c) [100] direction and (d) overview direction.

The optimized equilibrium lattice parameters for $\mathrm{AlN} / \mathrm{GaN} / \mathrm{InN}$ in the $P m n 2_{1}$ phase at zero pressure are listed in Table 1. The results show that the calculated values are in great agreement with other theoretical results and experimental results in Table 1, which shows that the present optimization and calculation are reliable. The results obtained by PBE functional are closer to experimental values, so the results obtained by PBE functional are used in this paper. The bond angles of Al-N, Ga-N and In-N in the $P m n 2_{1}$ phase range from 87.62 degrees to 117.91 degrees. In $P m n 2_{1}-\mathrm{AlN}, P m n 2_{1}-\mathrm{GaN}$ and $P m n 2_{1}$-InN, the bond lengths range from $1.872 \AA$ to $1.935 \AA$, $1.939 \AA$ to $2.009 \AA$ and $2.170 \AA$ to 2.243 $\AA$, respectively. For zb-AlN (zinc-blende AlN), zb-GaN, and zb-InN, the bond lengths are $1.905 \AA$, $1.975 \AA$ and $2.205 \AA$, respectively. For wz-AlN (wurtzite AlN), wz-GaN, and wz-InN, the bond lengths range from $1.901 \AA$ to $1.913 \AA, 1.973 \AA$ to $1.981 \AA$ and $2.202 \AA$ to $2.211 \AA$, respectively. The densities of $P m n 2_{1}$-AlN, $P m n 2_{1}-\mathrm{GaN}$ and $P m n 2_{1}-\mathrm{InN}$ are $3.150 \mathrm{~g} / \mathrm{cm}^{3}, 5.742 \mathrm{~g} / \mathrm{cm}^{3}$ and $6.351 \mathrm{~g} / \mathrm{cm}^{3}$, respectively, which are close to those of $\mathrm{AlN} / \mathrm{GaN} / \mathrm{InN}$ in the wurtzite phase.

Table 1. Lattice constants $a, b$, and $c(\AA)$ and density $\rho\left(\mathrm{g} \mathrm{cm}^{-3}\right)$ for $\mathrm{AlN} / \mathrm{GaN} / \mathrm{InN}$ in the $P m n 2_{1}$ phase.

\begin{tabular}{cccccc}
\hline Structure & & $\boldsymbol{a}$ & $\boldsymbol{b}$ & $\boldsymbol{c}$ & $\boldsymbol{\rho}$ \\
\hline Pmn $2_{1}$-AlN & GGA & 3.130 & 10.832 & 5.099 & 3.150 \\
Pmn $2_{1}$-GaN & GGA & 3.231 & 11.202 & 5.352 & 5.742 \\
Pmn $2_{1}$-InN & GGA & 3.617 & 12.528 & 5.946 & 6.351 \\
\hline \multirow{2}{*}{ wz-AlN } & GGA & 3.125 & & 5.009 & 3.206 \\
& LDA & 3.066 & & 4.905 & 3.408 \\
& Exp. ${ }^{a}$ & 3.111 & & 4.978 & \\
\hline \multirow{2}{*}{ wz-GaN } & GGA & 3.227 & & 5.258 & 5.865 \\
& LDA & 3.158 & & 5.149 & 6.254 \\
& Exp. ${ }^{a}$ & 3.192 & & 5.166 & \\
\hline \multirow{2}{*}{ wz-InN } & GGA & 3.611 & & 5.842 & 6.485 \\
& LDA & 3.531 & & 5.714 & 6.936 \\
& Exp. ${ }^{a}$ & 3.533 & & 5.639 & \\
\hline
\end{tabular}


Table 1. Cont.

\begin{tabular}{cccccc}
\hline Structure & & $\boldsymbol{a}$ & $\boldsymbol{b}$ & $\boldsymbol{c}$ & $\boldsymbol{\rho}$ \\
\hline zb-AlN & GGA & 4.399 & & & 3.198 \\
& LDA & 4.309 & & & 3.404 \\
& Exp. ${ }^{\mathrm{b}}$ & 4.370 & & \\
\hline zb-GaN & GGA & 4.561 & & 5.862 \\
& LDA & 4.466 & & 6.248 \\
& Exp. ${ }^{\mathrm{c}}$ & 4.490 & & \\
\hline zb-InN & GGA & 5.092 & & 6.482 \\
& LDA & 4.977 & 9.642 \\
\hline
\end{tabular}

${ }^{\mathrm{a}}$ Reference [39]; ${ }^{\mathrm{b}}$ Reference [40]; ${ }^{\mathrm{c}}$ Reference [41].

\subsection{Stability and Mechanical Properties}

The phonon spectra of AlN/GaN/InN in the Pmn2 1 phase were calculated under ambient conditions (see Figure 2) in this work. There is no imaginary frequency throughout the Brillouin zone, which means $P m n 2_{1}$-AlN, $P m n 2_{1}$-GaN and $P m n 2_{1}$-InN are all dynamically stable. The relative enthalpies at zero pressure are also calculated using the following expression:

$$
\Delta H=\left(E_{\text {total }}-n_{X} E_{\text {solid }}^{X}-n_{N} E_{\text {solid }}^{N}\right) /\left(n_{X}+n_{N}\right)
$$

where the $E_{\text {total }}$ is the total energy of $P m n 2_{1}-\mathrm{XN}(\mathrm{X}=\mathrm{Al}, \mathrm{Ga}, \mathrm{In})$; the $n_{\mathrm{X}}$ is the number of $\mathrm{Al} / \mathrm{Ga} / \mathrm{In}$ atoms in the cell; the $n_{N}$ is the number of $\mathrm{N}$ atoms in the cell; $E_{\text {solid }}^{X}$ is the energy of one $\mathrm{X}(\mathrm{X}=\mathrm{Al}$, $\mathrm{Ga}, \mathrm{In})$ atom in elemental $X\left(X=\right.$ aluminium, gallium, indium). $E_{\text {solid }}^{N}$ is the energy of one nitrogen atom in elemental nitrogen. For AlN, the enthalpies relative to zb-AlN and wz-AlN are $0.004 \mathrm{eV}$ per formula unit and $0.045 \mathrm{eV}$ per formula unit. For $\mathrm{GaN}$, the enthalpies relative to $\mathrm{zb}-\mathrm{GaN}$ and wz-GaN are $0.055 \mathrm{eV}$ per formula unit and $0.066 \mathrm{eV}$ per formula unit. Finally, for $\mathrm{InN}$, the enthalpies relative to zb-InN and wz-InN are $0.066 \mathrm{eV}$ per formula unit and $0.054 \mathrm{eV}$ per formula unit. Compared with other reported III-nitride polymorphs, $P m n 2_{1}$-AlN $(0.045 \mathrm{eV} /$ f.u. $)$ is more favorable than Pnma-AlN (0.232 eV/f.u.) [42], Cmcm-AlN (0.206 eV/f.u.) and Pbca-AlN (0.075 eV/f.u.) [30]. As seen from the enthalpies relative to $\mathrm{wz}-\mathrm{GaN}, P m n 2_{1}-\mathrm{GaN}(0.066 \mathrm{eV} \mathrm{eV} /$ f.u. $)$ is more favorable than Pnma-GaN (0.264 eV/f.u.) [43]. The results reveal that $P m n 2_{1}$-AlN and $P m n 2_{1}-\mathrm{GaN}$ are more favorable than most proposed polymorphs of AlN and GaN [30,42,43].

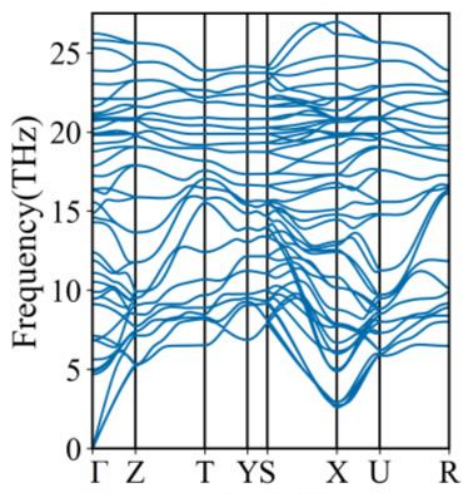

(a) AIN

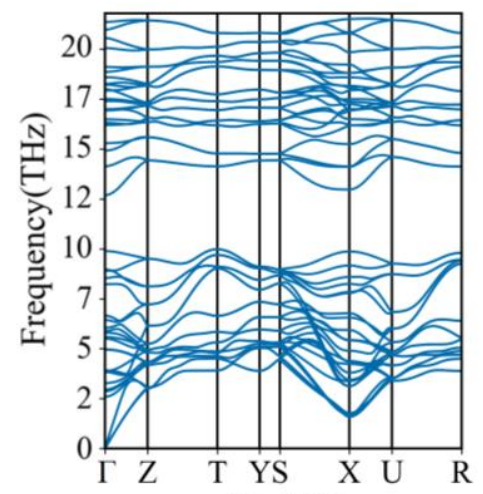

(b) $\mathrm{GaN}$

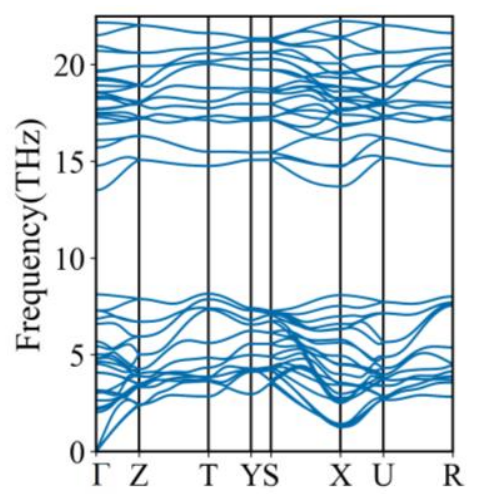

(c) $\mathrm{InN}$

Figure 2. The phonon spectra of (a) $P m n 2_{1}-\mathrm{AlN}$, (b) $P m n 2_{1}-\mathrm{GaN}$ and (c) $P m n 2_{1}-\mathrm{InN}$.

Table 2 shows the elastic constants and elastic modulus for AlN/GaN/InN in the $P m n 2_{1}$ phase, together with reported calculated and experimental results for comparison [44-46]. There are nine 
independent elastic constants for the orthorhombic phase, namely, $C_{11}, C_{12}, C_{13}, C_{22}, C_{23}, C_{33}, C_{44}, C_{55}$ and $C_{66}$. The mechanical stability criteria [47] of the orthorhombic structure are given as follows:

$$
\begin{gathered}
C_{11}>0, C_{12}>0, C_{13}>0, C_{22}>0, C_{23}>0, C_{33}>0, C_{44}>0, C_{55}>0, C_{66}>0, \\
{\left[C_{11}+C_{22}+C_{33}+2\left(C_{12}+C_{13}+C_{23}\right)\right]>0,} \\
\left(C_{11}+C_{22}-2 C_{12}\right)>0,\left(C_{11}+C_{33}-2 C_{13}\right)>0,\left(C_{22}+C_{33}-2 C_{23}\right)>0,
\end{gathered}
$$

The calculated elastic constants of $P m n 2_{1}-\mathrm{AlN}, P m n 2_{1}-\mathrm{GaN}$, and $P m n 2_{1}-\mathrm{InN}$ indicate that these structures are mechanically stable. According to the elastic constants listed in Table 2, the $C_{11}$ values of $P m n 2_{1}-\mathrm{AlN}, P m n 2_{1}-\mathrm{GaN}$, and Pmn $2_{1}-\mathrm{InN}$ are larger than those of wz-AlN/GaN/InN and $\mathrm{zb}-\mathrm{AlN} / \mathrm{GaN} / \mathrm{InN}$, which means that all three proposed polymorphs possess a better compression resistance in the $x$ direction than its corresponding III-nitride in the wurtzite phase and zinc-blende phase. Additionally, the $C_{33}$ values of $P m n 2_{1}-\mathrm{AlN} / \mathrm{GaN} / \mathrm{InN}$ are smaller than those of wz-AlN/GaN/InN and $\mathrm{zb}-\mathrm{AlN} / \mathrm{GaN} / \mathrm{InN}$, which reveal a better deformability along the $z$ direction.

The bulk modulus $(B)$ and shear modulus $(G)$ were calculated by using the Voigt-Reuss-Hill approximation [48], which are defined as $B=\left(B_{V}+B_{R}\right) / 2, G=\left(G_{V}+G_{R}\right) / 2$. Where $B_{V}$ means the Voigt approximation of bulk modulus $B ; B_{R}$ is the Reuss approximation of bulk modulus $B ; G_{V}$ means the Voigt approximation of shear modulus $G$; and $G_{R}$ is the Reuss approximation of shear modulus $G$.

The Young's modulus $E$ is used to offer a measure of the stiffness of a solid. The larger the value of $E$ is, the stiffer the material is [49]. The Young's modulus $E$ and Poisson's ratio $v$ were determined as follows [50]: $E=9 B G /(3 B+G), v=(3 B-2 G) /[2(3 B+G)]$. The obtained results are listed in Table 2. The calculated bulk modulus $B$ and shear modulus $G$ of $P m n 2_{1}-\mathrm{AlN} / \mathrm{GaN} / \mathrm{InN}$ are slightly less than those of wz-AlN/GaN/InN and zb-AlN/GaN/InN. The shear modulus is less than the bulk modulus for $P m n 2_{1}-\mathrm{AlN} / \mathrm{GaN} / \mathrm{InN}$. The values of $B / G$ and Poisson's ratio are associated with brittleness or ductility. If $B / G>1.75$ [51], a material is characterized as ductile; otherwise, the material has a brittle character. Poisson's ratio $<0.26$ indicates brittle compounds [52]. Obviously, Pmn $2_{1}$-AlN and Pmn $2_{1}-\mathrm{GaN}$ exhibit

\begin{tabular}{|c|c|c|c|c|c|c|c|c|c|c|c|c|c|c|c|}
\hline Structure & $C_{11}$ & $C_{12}$ & $C_{13}$ & $C_{22}$ & $C_{23}$ & $C_{33}$ & $C_{44}$ & $C_{55}$ & $C_{66}$ & $B$ & $G$ & $B / G$ & $E$ & $v$ & $H_{v}$ \\
\hline$P m n 2_{1}$-AlN & 383 & 122 & 97 & 352 & 89 & 294 & 117 & 112 & 115 & 181 & 116 & 1.56 & 288 & 0.235 & 16.3 \\
\hline wz-AlN & $\begin{array}{c}376 \\
345^{\mathrm{a}}\end{array}$ & $\begin{array}{l}118 \\
125\end{array}$ & $\begin{array}{c}88 \\
120\end{array}$ & & & $\begin{array}{l}353 \\
395\end{array}$ & $\begin{array}{l}113 \\
118\end{array}$ & & $\begin{array}{l}129 \\
110\end{array}$ & 188 & 125 & 1.50 & 307 & 0.227 & $\begin{array}{l}18.0 \\
18^{\mathrm{d}}\end{array}$ \\
\hline zb-AlN & $\begin{array}{c}276 \\
304^{b}\end{array}$ & $\begin{array}{l}143 \\
160\end{array}$ & & & & & $\begin{array}{l}181 \\
193\end{array}$ & & & 187 & 121 & 1.54 & 299 & 0.233 & 17.0 \\
\hline Pmn $2_{1}$-GaN & 333 & 109 & 84 & 299 & 75 & 294 & 87 & 85 & 94 & 162 & 97 & 1.68 & 241 & 0.251 & 12.8 \\
\hline wz-GaN & $\begin{array}{c}322 \\
390^{c}\end{array}$ & $\begin{array}{l}102 \\
145\end{array}$ & $\begin{array}{c}69 \\
106\end{array}$ & & & $\begin{array}{l}361 \\
398\end{array}$ & $\begin{array}{c}89 \\
105\end{array}$ & & $\begin{array}{l}110 \\
123\end{array}$ & 165 & 107 & 1.54 & 264 & 0.233 & $\begin{array}{c}15.5 \\
15.1^{\mathrm{d}}\end{array}$ \\
\hline zb-GaN & $\begin{array}{c}249 \\
293^{b}\end{array}$ & $\begin{array}{l}127 \\
159\end{array}$ & & & & & $\begin{array}{l}151 \\
155\end{array}$ & & & 168 & 105 & 1.60 & 260 & 0.242 & 14.5 \\
\hline$P m n 2_{1}-\mathrm{InN}$ & 207 & 91 & 74 & 185 & 68 & 168 & 42 & 42 & 47 & 113 & 48 & 2.38 & 125 & 0.316 & 3.9 \\
\hline wz-InN & $\begin{array}{c}194 \\
223^{b}\end{array}$ & $\begin{array}{c}90 \\
115\end{array}$ & $\begin{array}{l}64 \\
92\end{array}$ & & & $\begin{array}{l}202 \\
224\end{array}$ & $\begin{array}{l}48 \\
48\end{array}$ & & 52 & 114 & 54 & 2.12 & 140 & 0.296 & $\begin{array}{c}5.6 \\
5.1^{\mathrm{d}}\end{array}$ \\
\hline $\mathrm{zb}-\mathrm{InN}$ & $\begin{array}{c}154 \\
187^{b}\end{array}$ & $\begin{array}{l}101 \\
125\end{array}$ & & & & & $\begin{array}{l}87 \\
86\end{array}$ & & & 119 & 54 & 2.18 & 142 & 0.301 & 5.3 \\
\hline
\end{tabular}
brittle character, whereas $P m n 2_{1}$-InN behaves in a ductile manner.

Table 2. The calculated elastic constants (GPa) and elastic modulus (GPa) of $P m n 2_{1}$-AlN/GaN/InN.

${ }^{\mathrm{a}}$ Reference [39]; ${ }^{\mathrm{b}}$ Reference [44]; ${ }^{\mathrm{c}}$ Reference [46]; ${ }^{\mathrm{d}}$ Reference [53].

The Vickers hardness (Hv) was calculated by adopting Chen's formula based on an empirical scheme [53]:

$$
H_{v}=2\left(k^{2} G\right)^{0.585}-3 ; k=G / B
$$


The calculated and experimental hardness values are presented in Table 2 . The calculated hardness reveals that the proposed $P m n 2_{1}$-AlN and $P m n 2_{1}-\mathrm{GaN}$ possess a high Vickers hardness of $16.3 \mathrm{GPa}$ and $12.8 \mathrm{GPa}$; however, $P m n 2_{1}$-InN possesses a Vickers hardness of $3.9 \mathrm{GPa}$. The results show that in the $P m n 2_{1}$, zinc-blende and wurtzite phases, AlN possesses the highest hardness among these three polymorphs, the hardness of $\mathrm{GaN}$ is slightly lower than that of $\mathrm{AlN}$, and $\mathrm{InN}$ possesses the lowest hardness.

\subsection{Mechanical Anisotropic Properties}

It is well-known that the anisotropy of elasticity is an important implication in engineering science and crystal physics. Figure 3 shows the variation in Young's modulus for Pmn $2_{1}$-AlN/GaN/InN with three-dimensional crystallographic directions. The directional dependence of the Young's modulus $E$ for the orthorhombic crystal is [54]:

$$
\begin{aligned}
E^{-1}= & m_{1}^{4} S_{11}+m_{2}^{4} S_{22}+m_{3}^{4} S_{33}+2 m_{1}^{2} m_{2}^{2} S_{12}+2 m_{1}^{2} m_{3}^{2} S_{13}+ \\
& 2 m_{2}^{2} m_{3}^{2} S_{23}+m_{1}^{2} m_{2}^{2} S_{66}+m_{1}^{2} m_{3}^{2} S_{55}+m_{2}^{2} m_{2}^{2} S_{44}
\end{aligned}
$$

where $S_{\mathrm{ij}}$ refers to the elastic compliance constants and $m_{1}, m_{2}$, and $m_{3}$ are the direct cosines of the [uv w] direction. Figure 3 reveals that $P m n 2_{1}$-AlN possesses the smallest elastic anisotropy and largest Young's modulus among these three polymorphs. $P m n 2_{1}-\mathrm{GaN}$ and $P m n 2_{1}-\mathrm{InN}$ show a larger elastic anisotropy in the $y z$ plane and $x z$ plane. The $E_{\max } / E_{\min }$ ratios of $P m n 2_{1}-\mathrm{AlN}, P m n 2_{1}-\mathrm{GaN}$ and $P m n 2_{1}-\mathrm{InN}$ are 1.26, 1.26 and 1.32, respectively. The calculated results show that the elastic anisotropy of the Young's modulus for $P m n 2_{1}$-AlN/GaN/InN reflects a slight increase, from $P m n 2_{1}$-AlN to $P m n 2_{1}-\mathrm{GaN}$ and then to $P m n 2_{1}-\mathrm{InN}$.
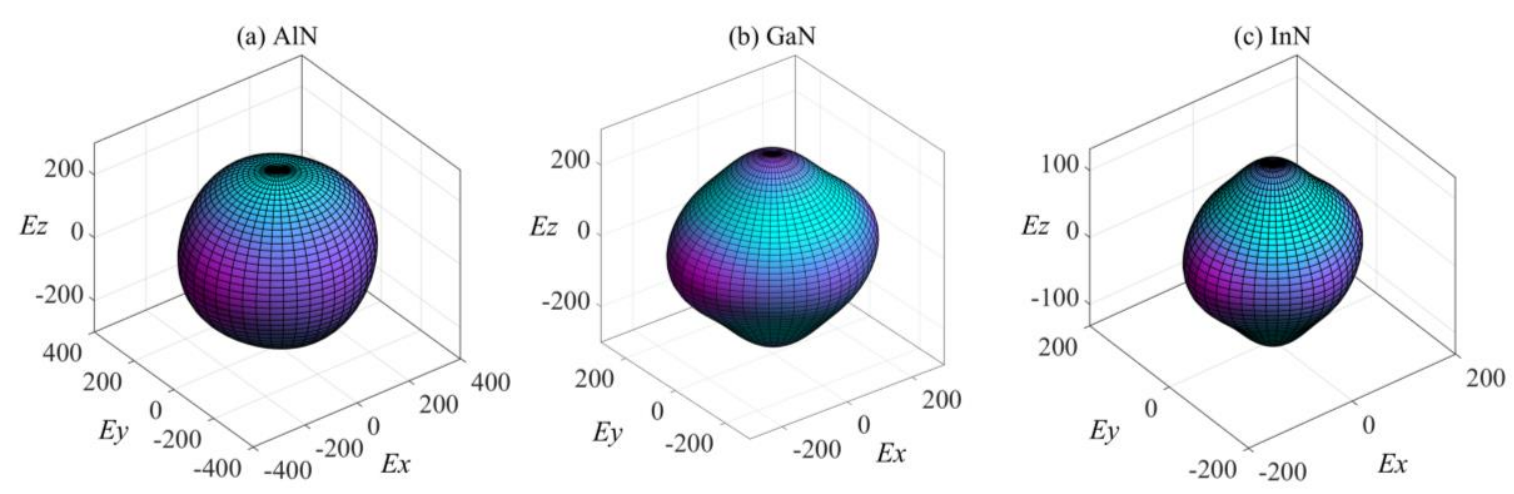

Figure 3. The surface construction of Young's modulus for (a) $P m n 2_{1}-\mathrm{AlN}$, (b) $P m n 2_{1}-\mathrm{GaN}$ and (c) Pmn $2_{1}$-InN.

To further understand the elastic anisotropy of the Young's modulus along different directions, the dependence of the Young's modulus on orientation was investigated by taking the tensile axis within a specific plane. Let $\alpha$ be the angle between $\left[\begin{array}{lll}1 & 0 & 0\end{array}\right]$ and $\left[\begin{array}{lll}u & v & 0\end{array}\right]$ for the $x y$ plane; then, the Young's modulus between $\left[\begin{array}{lll}1 & 0 & 0\end{array}\right]$ and $[u v 0]$ for the $x y$ plane can be expressed as:

$$
E^{-1}=S_{11} \cos ^{4} \alpha+S_{22} \sin ^{4} \alpha+2 S_{12} \sin ^{2} \alpha \cos ^{2} \alpha+S_{66} \sin ^{2} \alpha \cos ^{2} \alpha
$$

Let $\beta$ be the angle between $\left[\begin{array}{lll}0 & 0 & 1\end{array}\right]$ and $\left[\begin{array}{lll}u & 0 & w\end{array}\right]$ for the $\left(\begin{array}{lll}0 & 1 & 0\end{array}\right)$ plane; then, the Young's modulus between $\left[\begin{array}{lll}0 & 0 & 1\end{array}\right]$ and $[u \quad 0 w]$ for the $x z$ plane can be expressed as:

$$
E^{-1}=S_{11} \sin ^{4} \beta+S_{33} \cos ^{4} \beta+\left[2 S_{13} \sin ^{2} 2 \beta+S_{55} \sin ^{2} 2 \beta\right] / 4
$$


Let $\gamma$ be the angle between $\left[\begin{array}{lll}0 & 0 & 1\end{array}\right]$ and $\left[\begin{array}{lll}0 & v & w\end{array}\right]$ for the $\left(\begin{array}{lll}0 & 0 & 1\end{array}\right)$ plane; Then, the Young's modulus between $\left[\begin{array}{lll}0 & 0 & 1\end{array}\right]$ and $\left[\begin{array}{lll}0 & w & w\end{array}\right]$ for the $x y$ plane can be expressed as:

$$
E^{-1}=S_{22} \sin ^{4} \gamma+S_{33} \cos ^{4} \gamma+\left[2 S_{33} \sin ^{2} 2 \gamma+S_{44} \sin ^{2} 2 \gamma\right] / 4
$$

Two-dimensional representations of the Young's modulus for $P m n 2_{1}$-AlN/GaN/InN are illustrated in Figure 4. The lines representing $P m n 2_{1}-\mathrm{AlN}, P m n 2_{1}-\mathrm{GaN}$, and $P m n 2_{1}-\mathrm{InN}$ are shown in blue, red, and green, respectively. From Figures 3 and 4, we find that $P m n 2_{1}-\mathrm{InN}$ exhibits the smallest elastic anisotropy in the Young's modulus and that $P m n 2_{1}$-AlN exhibits the largest elastic anisotropy. For these three primary planes, the maximum values for $P m n 2_{1}-\mathrm{AlN}, P m n 2_{1}-\mathrm{GaN}$, and $P m n 2_{1}-\mathrm{InN}$ all occur in the $x z$ plane and $x y$ plane, and the minimum values occur in the $y z$ plane. In addition, the $x y$ plane of $P m n 2_{1}$-AlN, $P m n 2_{1}$-GaN, and $P m n 2_{1}$-InN exhibits the smallest elastic anisotropy in the Young's modulus, and the $E_{\max } / E_{\min }$ ratios are 1.09, 1.13 and 1.14, respectively. The $x z$ plane exhibits the greatest elastic anisotropy in the Young's modulus for $P m n 2_{1}-\mathrm{AlN} / \mathrm{GaN} / \mathrm{InN}$.

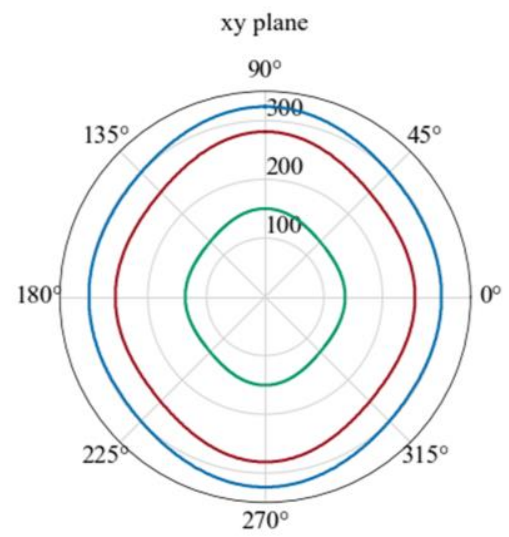

\begin{tabular}{|c|c|c|c|}
\hline xy plane & Max & Min & ratio \\
\hline AlN & 323.81 & 296.86 & 1.09 \\
\hline GaN & 281.15 & 249.71 & 1.13 \\
\hline InN & 150.27 & 131.68 & 1.14 \\
\hline
\end{tabular}

(a)

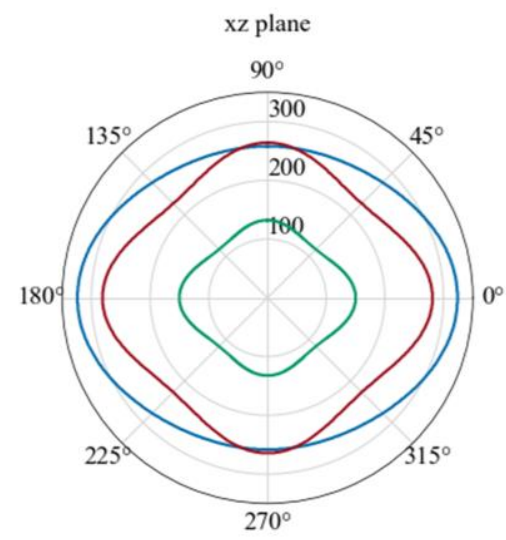

\begin{tabular}{|c|c|c|c|}
\hline xz plane & Max & Min & ratio \\
\hline $\mathrm{AlN}$ & 323.81 & 258.14 & 1.25 \\
\hline $\mathrm{GaN}$ & 281.15 & 226.97 & 1.24 \\
\hline $\mathrm{InN}$ & 150.26 & 116.15 & 1.29 \\
\hline
\end{tabular}

(b)

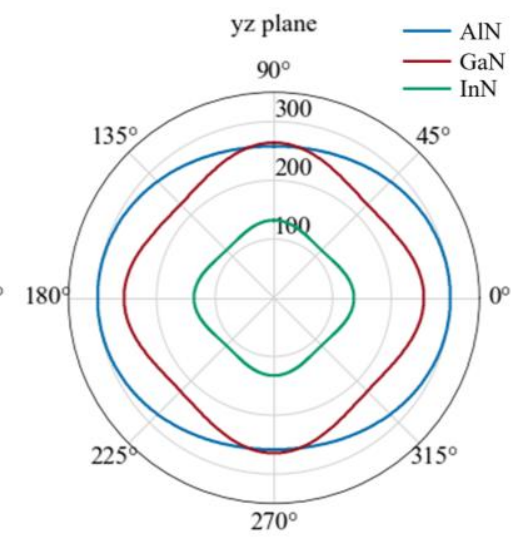

\begin{tabular}{|c|c|c|c|}
\hline yz plane & Max & Min & ratio \\
\hline AIN & 300.48 & 258.14 & 1.16 \\
\hline GaN & 264.21 & 224.83 & 1.18 \\
\hline InN & 136.27 & 114.63 & 1.19 \\
\hline
\end{tabular}

(c)

Figure 4. Two-dimensional representation of the Young's modulus in the $x y$ plane, $x z$ plane and $y z$ plane for (a) $P m n 2_{1}$-AlN, (b) $P m n 2_{1}-\mathrm{GaN}$ and (c) $P m n 2_{1}-\mathrm{InN}$.

In addition, apart from the surface construction and two-dimensional representation of Young's modulus, the universal anisotropic index $A^{\mathrm{U}}$ [55] is also calculated for deeper investigation in this work. $A^{\mathrm{U}}$ is defined as $A^{\mathrm{U}}=5 G_{V} / G_{R}+B_{V} / B_{R}-6$, where $B_{\mathrm{V}}\left(B_{\mathrm{R}}\right)$ and $G_{\mathrm{V}}\left(G_{\mathrm{R}}\right)$ represent the symbols of the bulk modulus and shear modulus at Voigt (Reuss) bounds, respectively. The $A^{\mathrm{U}}$ of $P m n 2_{1}$-AlN/GaN/InN are $0.0454,0.0801$ and 0.1006 , respectively. The calculated $A^{\mathrm{U}}$ is similar to the three-dimensional and two-dimensional representation of the Young's modulus, it also shows an increasing tendency with the group III element ( $\mathrm{Al}, \mathrm{Ga}, \mathrm{In})$ atomic number.

\subsection{Electrical and Thermal Properties}

The energy band structure of the material determines a variety of properties, especially its electronic and optical properties. The electronic band structure, together with partial density of state (PDOS) of $P m n 2_{1}$-AlN/GaN/InN are shown in Figure 5. All three proposed compounds are semiconductor materials with direct bandgaps at $\mathrm{G}$ points of $5.17 \mathrm{eV}\left(P m n 2_{1}-\mathrm{AlN}\right), 2.77 \mathrm{eV}\left(P m n 2_{1}-\mathrm{GaN}\right)$ and $0.47 \mathrm{eV}$ $\left(P m n 2_{1}\right.$-InN), notably $P m n 2_{1}$-AlN and $P m n 2_{1}-\mathrm{GaN}$, which are wide bandgap semiconductors [56]. In a light emitting diode, only the direct transition process can produce light, which is the main transition method for direct semiconductors. The wavelength of light is mostly determined by the energy band 
gap of the semiconductors [57]. The band gap of $P m n 2_{1}-\mathrm{GaN}$ is $2.77 \mathrm{eV}$, which is lower than that of wz-GaN (3.4 eV) [58] and corresponds to the blue light region, making it a potential material for blue LEDs without adulteration. The energy band gaps of $P m n 2_{1}$-AlN and $P m n 2_{1}$-InN correspond to the ultraviolet region and infrared region, respectively. This suggests that $P m n 2_{1}$-AlN and $P m n 2_{1}$-InN have the potential to produce optoelectronic devices.
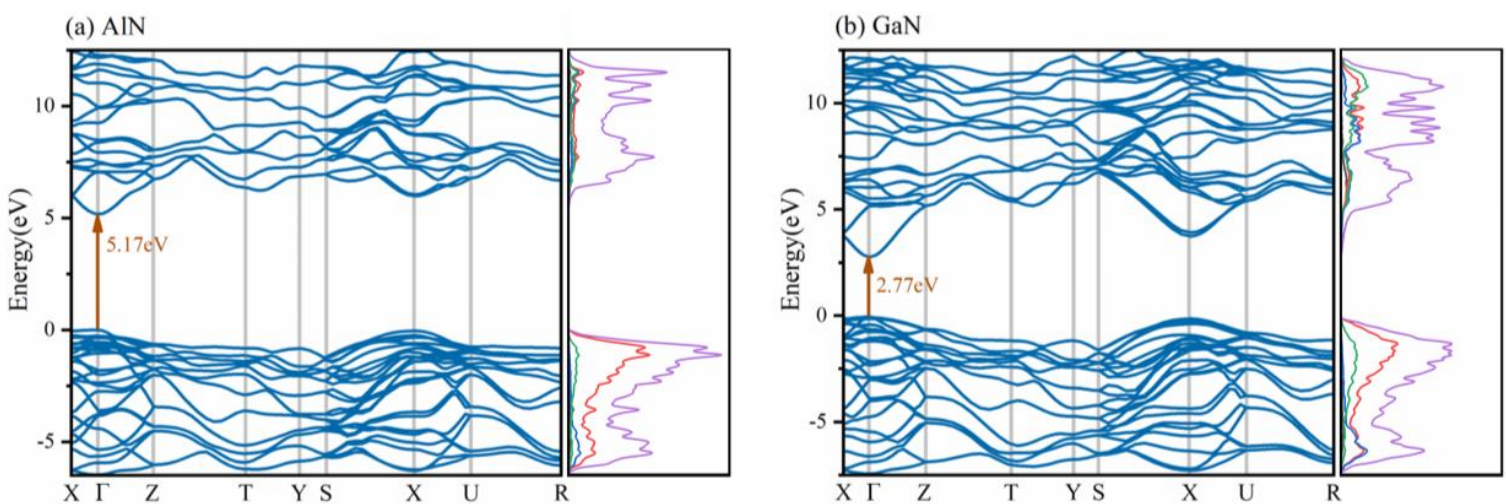

(c) $\mathrm{InN}$

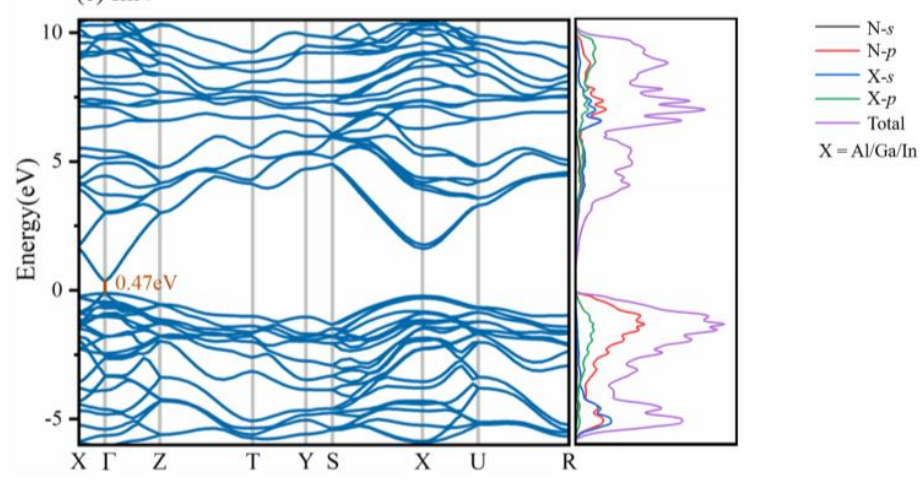

Figure 5. Electronic band structure and Partial density of states for (a) $P m n 2_{1}$-AlN, (b) $P m n 2_{1}-\mathrm{GaN}$ and (c) $P m n 2_{1}$-InN.

The lines represent the total DOS, N-s, N-p, X-s, and X-p $(\mathrm{X}=\mathrm{Al}, \mathrm{Ga}, \mathrm{In})$ are set to purple, black, red, blue and green, respectively. According to the PDOS diagram of Pmn $2_{1}$-AlN/GaN/InN, the density of states mainly comes from $\mathrm{N}-p$ orbitals. Below $0 \mathrm{eV}$, the total DOS in the valence band originates mainly from N-p orbitals for these three compounds. Above $0 \mathrm{eV}$, the N-p, X-s and X-p orbitals $(\mathrm{X}=\mathrm{Al}$, $\mathrm{Ga}$, In) contribute greatly and overlap with each other. In addition, the N-s orbitals contribute the smallest proportion in the valance band and conduction band. For Pmn $2_{1}-\mathrm{AlN} / \mathrm{GaN} / \mathrm{InN}$, the peaks are all present in the energy region close to $0 \mathrm{eV}(-2$ to $0 \mathrm{eV})$, and the DOS is mainly due to the contributions from N- $p$ orbitals; the contribution of other electron orbitals is relatively small. These DOS peaks depend on the N-p/X-p (X=Al, Ga, In) bonding orbital contribution. The results show that covalent $\mathrm{N}-\mathrm{X}(\mathrm{X}=\mathrm{Al}, \mathrm{Ga}, \mathrm{In})$ interactions exist.

The effective mass is also calculated by quadratic polynomial fitting of valence and conduction bands along the $x, y$, and $z$ directions. The effective mass can be determined as follows: $\left(\mathrm{m}^{*}\right)^{-1}=\left(1 / t s h^{2}\right)\left(\partial^{2} E / \partial k^{2}\right)$. The calculated hole effective mass and electron effective mass of $P m n 2_{1}-\mathrm{AlN} / \mathrm{GaN} / \mathrm{InN}, \mathrm{zb}-\mathrm{AlN} / \mathrm{GaN} / \mathrm{InN}$ and the experimental values for comparison are listed in Table 3. The electron effective mass of these three proposed III-nitride polymorphs along the $x, y$ and $z$ directions gradually decrease, whereas the electron effective mass along these three directions are almost the same. For Pmn $2_{1}-\mathrm{AlN} / \mathrm{GaN} / \mathrm{InN}$, the largest hole effective mass occurs along the $y$ direction, and the smallest occurs along the $z$ direction. For Pmn $2_{1}$-AlN, the hole effective mass and the electron effective mass along the $x, y$ and $z$ directions are larger than those of $P m n 2_{1}-\mathrm{GaN}, P m n 2_{1}$-InN 
and $\mathrm{zb}-\mathrm{AlN} / \mathrm{GaN} / \mathrm{InN}$. For $P m n 2_{1}-\mathrm{GaN}$, the hole effective mass along the $y$ direction is close to that of $P m n 2_{1}$-InN. Finally, for Pmn $2_{1}-$ InN, the hole effective mass along the $z$ direction is much smaller than that of $\mathrm{zb}-\mathrm{InN}$, and the electron effective mass of Pmn $2_{1}-\mathrm{InN}$ along all directions is close to that of zb-InN.

Table 3. The calculated effective mass (in $\mathrm{m}_{0}$ ) along the $x, y$, and $z$ directions for $P m n 2_{1}-\mathrm{AlN}, P m n 2_{1}-\mathrm{GaN}$, and $P m n 2{ }_{1}$-InN.

\begin{tabular}{|c|c|c|}
\hline \multirow{2}{*}{$x$ Direction } & Hole Effective Mass & Electron Effective Mass \\
\hline & $P m n 2_{1} /$ zinc-blende/Ref & $P m n 2_{1} /$ zinc-blende/Ref \\
\hline AlN & $3.29 / 1.23 / 1.02^{\mathrm{a}}$ & $0.32 / 0.33 / 0.23^{a}$ \\
\hline $\mathrm{GaN}$ & $1.95 / 0.90 / 0.80^{\mathrm{a}}$ & $0.16 / 0.14 / 0.14^{a}$ \\
\hline $\mathrm{InN}$ & $1.14 / 0.94 / 1.08^{a}$ & $0.08 / 0.08 / 0.13^{a}$ \\
\hline \multirow{2}{*}{$y$ Direction } & Hole Effective Mass & Electron Effective Mass \\
\hline & $P m n 2_{1} /$ zinc-blende & $P m n 2_{1} /$ zinc-blende/Ref \\
\hline AlN & $5.31 / 1.23$ & $0.31 / 0.33 / 0.23^{a}$ \\
\hline $\mathrm{GaN}$ & $2.58 / 0.90$ & $0.16 / 0.14 / 0.14^{\mathrm{a}}$ \\
\hline $\operatorname{InN}$ & $2.55 / 0.94$ & $0.08 / 0.08 / 0.13^{a}$ \\
\hline \multirow{2}{*}{$z$ Direction } & Hole Effective Mass & Electron Effective Mass \\
\hline & $P m n 2_{1} /$ zinc-blende/Ref & Pmn $2_{1} /$ zinc-blende/Ref \\
\hline AlN & $0.27 / 1.23 / 1.33^{\mathrm{b}}$ & $0.30 / 0.33 / 0.23^{a}$ \\
\hline $\mathrm{GaN}$ & $0.15 / 0.90 / 0.81^{b}$ & $0.15 / 0.14 / 0.14^{\mathrm{a}}$ \\
\hline $\operatorname{InN}$ & $0.09 / 0.94 / 0.84^{b}$ & $0.08 / 0.08 / 0.13^{\mathrm{a}}$ \\
\hline
\end{tabular}

\section{Conclusions}

In summary, we investigated the structural, stability, mechanical and electronic properties of $P m n 2_{1}-\mathrm{AlN} / \mathrm{GaN} / \mathrm{InN}$. Pmn $2_{1}-\mathrm{AlN} / \mathrm{GaN} / \mathrm{InN}$ are mechanically and dynamically stable. The relative enthalpies of Pnma-AlN and Pmn $2_{1}-$ GaN are more favorable than those of most predicted III-nitride polymorphs. The elastic constants indicate that Pmn $2_{1}-\mathrm{AlN} / \mathrm{GaN} / \mathrm{InN}$ possess better deformation resistance properties in the $x$ direction and better deformability along the $z$ direction than wz-AlN/GaN/InN and zb-AlN/GaN/InN. The calculated $H_{v}$ values of $P m n 2_{1}-\mathrm{AlN}$ and $P m n 2_{1}-\mathrm{GaN}$ reveal that $P m n 2_{1}-\mathrm{AlN}$ and $P m n 2_{1}-\mathrm{GaN}$ possess a high hardness of $16.3 \mathrm{GPa}$ and $12.8 \mathrm{GPa}$, respectively. $P m n 2_{1}$-AlN, $P m n 2_{1}-\mathrm{GaN}$ and $P m n 2_{1}-\mathrm{InN}$ exhibit similar elastic anisotropies. The electron effective mass of Pmn $2_{1}$-InN is smaller along all three directions than that of $\mathrm{zb}$-InN. In addition, the hole effective mass of $P m n 2_{1}-\mathrm{GaN}$ and $P m n 2_{1}-\mathrm{InN}$ along the $z$ direction are much smaller than those of $\mathrm{zb}-\mathrm{GaN}$ and zb-InN. Pmn $2_{1}$-AlN/GaN/InN are direct semiconductor materials with energy band gaps of $5.17 \mathrm{eV}$ (Pmn $\left.2_{1}-\mathrm{AlN}\right), 2.77 \mathrm{eV}\left(\mathrm{Pmn} 2_{1}-\mathrm{GaN}\right)$ and $0.47 \mathrm{eV}\left(P m n 2_{1}-\mathrm{InN}\right)$. Ultimately, $P m n 2_{1}-\mathrm{AlN}, P m n 2_{1}-\mathrm{GaN}$ and $P m n 2_{1}$-InN may have great potential industrial applications in the future due to their superior electronic and mechanical properties.

Author Contributions: Software, Z.Z. and L.K.; investigation, W.Z.; writing-original draft preparation, Z.Z.; writing-review and editing, W.Z., Y.S., C.C. and Y.Y; visualization, Z.Z.; project administration, W.Z., C.C. and Y.Y; funding acquisition, C.C. and Y.Y. All authors have read and agreed to the published version of the manuscript.

Funding: This research was funded by the National Natural Science Foundation of China, grant number 61974116.

Conflicts of Interest: The authors declare no conflicts of interest. 


\section{References}

1. Lin, H.-W.; Lu, Y.-J.; Chen, H.-Y.; Lee, H.-M.; Gwo, S. InGaN/GaN nanorod array white light-emitting diode. Appl. Phys. Lett. 2010, 97, 073101.

2. Serrano, J.; Rubio, A.; Hernández, E.; Muñoz, A.; Mujica, A. Theoretical study of the relative stability of structural phases in group-III nitrides at high pressures. Phys. Rev. B 2000, 62, 16612. [CrossRef]

3. Ueno, M.; Yoshida, M.; Onodera, A.; Shimomura, O.; Takemura, K. Stability of the wurtzite-type structure under high pressure: GaN and InN. Phys. Rev. B 1994, 49, 14. [CrossRef]

4. Zhang, W.; Chai, C.C.; Song, Y.X.; Fan, Q.Y.; Yang, Y.T. Structural, Mechanical, Anisotropic, and Thermal Properties of AlAs in oC12 and hP6 Phases under Pressure. Materials 2018, 11, 740. [CrossRef]

5. Takahashi, N.; Matsumoto, Y.; Nakamura, T. Investigations of structure and morphology of the AlN nano-pillar crystal films prepared by halide chemical vapor deposition under atmospheric pressure. J. Phys. Chem. Solids 2006, 67, 665-668. [CrossRef]

6. Miao, J.; Chai, C.; Zhang, W.; Song, Y.; Yang, Y. First-Principles Study on Structural, Mechanical, Anisotropic, Electronic and Thermal Properties of III-Phosphides: XP (X = Al, Ga, or In) in the P6422 Phase. Materials 2020, 13, 686. [CrossRef]

7. Muranaka, T.; Kikuchi, Y.; Yoshizawa, T.; Shirakawa, N.; Akimitsu, J. Superconductivity in carrier-doped silicon carbide. Sci. Technol. Adv. Mater. 2009, 9, 044204. [CrossRef]

8. Morkoc, H.; Strite, S.; Gao, G.; Lin, M.; Sverdlov, B.; Burns, M. Large-band-gap SiC, III-V nitride, and II-VI ZnSe-based semiconductor device technologies. J. Appl. Phys. 1994, 76, 1363-1398. [CrossRef]

9. Zhang, W.; Ristein, J.; Ley, L. Hydrogen-terminated diamond electrodes. II. Redox activity. Phys. Rev. E 2008, 78, 041603. [CrossRef]

10. Collins, A.T. The optical and electronic properties of semiconducting diamond. Philos. Trans. R. Soc. Lond. Ser. A Phys. Eng. Sci. 1993, 342, 233-244.

11. Zhang, W.; Chai, C.C.; Fan, Q.Y.; Weng, K.Q.; Yang, Y.T. Theoretical investigations of Ge1-x Sn (x) alloys $(\mathrm{x}=0,0.333,0.667,1)$ in $\mathrm{P} 4(2) / \mathrm{ncm}$ phase. J. Mater. Sci. 2018, 53, 9611-9626. [CrossRef]

12. Song, Y.X.; Chai, C.C.; Fan, Q.Y.; Zhang, W.; Yang, Y.T. Physical properties of Si-Ge alloys in C2/m phase: A comprehensive investigation. J. Phys. Condes. Matter 2019, 31, 12. [CrossRef] [PubMed]

13. Zhang, W.; Chai, C.C.; Fan, Q.Y.; Song, Y.X.; Yang, Y.T. PBCF-Graphene: A 2D Sp(2) Hybridized Honeycomb Carbon Allotrope with a Direct Band Gap. ChemNanoMat 2020, 6, 139-147. [CrossRef]

14. Zhang, W.; Chai, C.; Fan, Q.; Song, Y.; Yang, Y. Two novel superhard carbon allotropes with honeycomb structures. J. Appl. Phys. 2019, 126, 145704. [CrossRef]

15. Zhang, W.; Chai, C.; Fan, Q.; Song, Y.; Yang, Y. Penta-C20: A Superhard Direct Band Gap Carbon Allotrope Composed of Carbon Pentagon. Materials 2020, 13, 1926. [CrossRef]

16. Zhang, W.; Chai, C.; Fan, Q.; Song, Y.; Yang, Y. Six novel carbon and silicon allotropes with their potential application in photovoltaic field. J. Phys. Condens. Matter 2020, 32, 35. [CrossRef]

17. Fan, Q.; Zhao, Y.; Yu, X.; Song, Y.; Zhang, W.; Yun, S. Physical properties of a novel microporous carbon material. Diam. Relat. Mater. 2020, 106, 107831. [CrossRef]

18. Fan, Q.; Zhang, W.; Song, Y.; Zhang, W.; Yun, S. P63/mmc-Ge and their Si-Ge alloys with a mouldable direct band gap. Semicond. Sci. Technol. 2020, 35, 055012. [CrossRef]

19. Fan, Q.; Wang, H.; Song, Y.; Zhang, W.; Yun, S. Five carbon allotropes from Squaroglitter structures. Comput. Mater. Sci. 2020, 178, 109634. [CrossRef]

20. Liu, H.; Fan, Q.-Y.; Yang, F.; Yu, X.-H.; Zhang, W.; Yun, S.-N. tP40 carbon: A novel superhard carbon allotrope. Chin. Phys. B 2020. [CrossRef]

21. Yang, G.; Chen, B.F. Predicted a novel high-pressure superhard boron nitride phase. J. Alloys Compd. 2014, 598, 54-56. [CrossRef]

22. Liu, C.; Ma, M.; Yuan, X.; Sun, H.; Ying, P.; Xu, B.; Zhao, Z.; He, J. Metastable phases, phase transformation and properties of AlAs based on first-principle study. Comput. Mater. Sci. 2017, 128, 337-342. [CrossRef]

23. Xu, L.; Bu, W. Mechanical and thermodynamic properties of AlX (X=N, P, As) compounds. Int. J. Mod. Phys. B 2017, 31, 1750167. [CrossRef]

24. Zhang, Q.; Zou, Y.; Fan, Q.; Yang, Y. Physical Properties of XN (X= B, Al, Ga, In) in the Pm-3n phase: First-Principles Calc. Materials 2020, 13, 1280. [CrossRef] 
25. Zeng, Y.; Chiu, H.-C.; Rasool, M.; Brodusch, N.; Gauvin, R.; Jiang, D.-T.; Ryan, D.H.; Zaghib, K.; Demopoulos, G.P. Hydrothermal crystallization of Pmn21 $\mathrm{Li}_{2} \mathrm{FeSiO}_{4}$ hollow mesocrystals for Li-ion cathode application. Chem. Eng. J. 2019, 359, 1592-1602. [CrossRef]

26. Pandey, M.; Ramar, V.; Balaya, P.; Kshirsagar, R.J. Infrared Spectroscopy of $\mathrm{Li}_{2} \mathrm{MnSiO}_{4}$ : A cathode material for Li ion batteries. AIP Conf. Proc. 2015, 1665, 140044.

27. Fisher, C.A.; Kuganathan, N.; Islam, M.S. Defect chemistry and lithium-ion migration in polymorphs of the cathode material $\mathrm{Li}_{2} \mathrm{MnSiO}_{4}$. J. Mater. Chem. A 2013, 1, 4207-4214. [CrossRef]

28. Yang, R.; Zhu, C.; Wei, Q.; Du, Z. First-principles study of the properties of Pmn2 1-B1-x Al x N. Philos. Mag. 2017, 97, 3008-3026. [CrossRef]

29. Chittari, B.L. Dynamical stability of Pmn21 phase of $\mathrm{NH}_{3} \mathrm{BH}_{3}$ : A vdW density functional study. Philos. Mag. Lett. 2014, 94, 278-287. [CrossRef]

30. Liu, C.; Hu, M.; Luo, K.; Cui, L.; Yu, D.; Zhao, Z.; He, J. Novel high-pressure phases of AlN: A first-principles study. Comput. Mater. Sci. 2016, 117, 496-501. [CrossRef]

31. Hohenberg, P.; Kohn, W. Density Functional Theory (DFT). Phys. Rev. B 1964, 136, 864. [CrossRef]

32. Segall, M.; Lindan, P.J.; Probert, M.A.; Pickard, C.J.; Hasnip, P.J.; Clark, S.; Payne, M. First-principles simulation: Ideas, illustrations and the CASTEP code. J. Phys. Condens. Matter 2002, 14, 2717. [CrossRef]

33. Perdew, J.; Burke, K.; Ernzerhof, M. Generalized Gradient Approximation Made Simple. Phys. Rev. Lett. 1996, 77, 3865-3868. [CrossRef] [PubMed]

34. Ceperley, D.M.; Alder, B.J. Ground state of the electron gas by a stochastic method. Phys. Rev. Lett. 1980, 45, 566. [CrossRef]

35. Perdew, J.P.; Zunger, A. Self-interaction correction to density-functional approximations for many-electron systems. Phys. Rev. B 1981, 23, 5048. [CrossRef]

36. Head, J.D.; Zerner, M.C. A Broyden-Fletcher-Goldfarb-Shanno optimization procedure for molecular geometries. Chem. Phys. Lett. 1985, 122, 264-270. [CrossRef]

37. Baroni, S.; De Gironcoli, S.; Dal Corso, A.; Giannozzi, P. Phonons and related crystal properties from density-functional perturbation theory. Rev. Mod. Phys. 2001, 73, 515. [CrossRef]

38. Heyd, J.; Scuseria, G.E.; Ernzerhof, M. Hybrid functionals based on a screened Coulomb potential. J. Chem. Phys. 2003, 118, 8207-8215. [CrossRef]

39. Karch, K.; Bechstedt, F. Ab initio lattice dynamics of BN and AlN: Covalent versus ionic forces. Phys. Rev. B 1997, 56, 7404. [CrossRef]

40. Edgar, J.H. Properties of Group-III Nitrides; Institution of Electrical Engineers: London, UK, 1997.

41. Lei, T.; Fanciulli, M.; Molnar, R.; Moustakas, T.; Graham, R.; Scanlon, J. Epitaxial growth of zinc blende and wurtzitic gallium nitride thin films on (001) silicon. Appl. Phys. Lett. 1991, 59, 944-946. [CrossRef]

42. Fan, Q.; Zhang, W.; Yun, S.; Xu, J.; Song, Y. III-Nitride Polymorphs: XN (X=Al, Ga, In) in the Pnma Phase. Chem. A Eur. J. 2018, 24, 17280-17287. [CrossRef] [PubMed]

43. Fan, Q.; Chai, C.; Wei, Q.; Yang, J.; Zhou, P.; Zhang, D.; Yang, Y. A new phase of GaN. J. Chem. 2016, 2016, 8612892. [CrossRef]

44. Wright, A. Elastic properties of zinc-blende and wurtzite AlN, GaN, and InN. J. Appl. Phys. 1997, 82, 2833-2839. [CrossRef]

45. Shimada, K.; Sota, T.; Suzuki, K. First-principles study on electronic and elastic properties of BN, AlN, and GaN. J. Appl. Phys. 1998, 84, 4951-4958. [CrossRef]

46. Polian, A.; Grimsditch, M.; Grzegory, I. Elastic constants of gallium nitride. J. Appl. Phys. 1996, 79, $3343-3344$. [CrossRef]

47. Mouhat, F.; Coudert, F.-X. Necessary and sufficient elastic stability conditions in various crystal systems. Phys. Rev. B 2014, 90, 224104. [CrossRef]

48. Hill, R. The elastic behaviour of a crystalline aggregate. Proc. Phys. Soc. Sect. A 1952, 65, 349. [CrossRef]

49. Korozlu, N.; Colakoglu, K.; Deligoz, E.; Aydin, S. The elastic and mechanical properties of MB12 (M = Zr, Hf, Y, Lu) as a function of pressure. J. Alloys Compd. 2013, 546, 157-164. [CrossRef]

50. Watt, J.P. Hashin-Shtrikman bounds on the effective elastic moduli of polycrystals with monoclinic symmetry. J. Appl. Phys. 1980, 51, 1520-1524. [CrossRef]

51. Pugh, S. XCII. Relations between the elastic moduli and the plastic properties of polycrystalline pure metals. Lond. Edinb. Dublin Philos. Mag. J. Sci. 1954, 45, 823-843. [CrossRef] 
52. Lewandowski, J.; Wang, W.; Greer, A. Intrinsic plasticity or brittleness of metallic glasses. Philos. Mag. Lett. 2005, 85, 77-87. [CrossRef]

53. Chen, X.-Q.; Niu, H.; Li, D.; Li, Y. Modeling hardness of polycrystalline materials and bulk metallic glasses. Intermetallics 2011, 19, 1275-1281. [CrossRef]

54. Ting, T. On Anisotropic Elastic Materials for which Y'oung's Modulus E (n) is Independent of $n$ or the Shear Modulus G (n, m) is Independent of $\mathrm{n}$ and $\mathrm{m}$. J. Elast. 2005, 81, 271-292. [CrossRef]

55. Ranganathan, S.I.; Ostoja-Starzewski, M. Universal elastic anisotropy index. Phys. Rev. Lett. 2008, 101, 055504. [CrossRef]

56. Takahashi, K.; Yoshikawa, A.; Sandhu, A. Wide Bandgap Semiconductors; Springer: Berlin/Heidelberg, Germany, 2007; Volume 239.

57. Schubert, E.F. Light-Emitting Diodes, 2nd ed.; Cambridge University Press: Cambridge, UK, 2006.

58. Shan, W.; Schmidt, T.; Hauenstein, R.; Song, J.; Goldenberg, B. Pressure-dependent photoluminescence study of wurtzite GaN. Appl. Phys. Lett. 1995, 66, 3492-3494. [CrossRef]

59. Morkoç, H. Handbook of Nitride Semiconductors and Devices, Materials Properties, Physics and Growth; John Wiley \& Sons: Hoboken, NJ, USA, 2009; Volume 1.

60. Rinke, P.; Winkelnkemper, M.; Qteish, A.; Bimberg, D.; Neugebauer, J.; Scheffler, M. Consistent set of band parameters for the group-III nitrides AlN, GaN, and InN. Phys. Rev. B 2008, 77, 075202. [CrossRef]

(C) 2020 by the authors. Licensee MDPI, Basel, Switzerland. This article is an open access article distributed under the terms and conditions of the Creative Commons Attribution (CC BY) license (http://creativecommons.org/licenses/by/4.0/). 